\title{
Adults' Lack of a Usual Source of Care: A Matter of Preference?
}

\author{
Anthony J. Viera, MD, $M P H^{1,2}$ \\ Donald E. Pathman, MD MPH ${ }^{2,3}$ \\ Joanne M. Garrett, $\mathrm{PhD}^{1,4}$ \\ ${ }^{1}$ Robert Wood Johnson Clinical Scholars \\ Program, University of North Carolina at \\ Chapel Hill, Chapel Hill, NC \\ ${ }^{2}$ Department of Family Medicine, Uni- \\ versity of North Carolina at Chapel Hill, \\ Chapel Hill, NC
}

${ }^{3}$ Cecil G. Sheps Center for Health Services Research, University of North Carolina at Chapel Hill, Chapel Hill, NC

${ }^{4}$ Department of Obstetrics/Gynecology, University of North Carolina at Chapel Hill, Chapel Hill, NC
Conflicts of interest: none reported

\section{CORRESPONDING AUTHOR}

Anthony J. Viera, MD

Department of Family Medicine

101 Manning Dr, CB 7595

UNC Chapel Hill

Chapel Hill, NC 27599

anthony_viera@med.unc.edu

\begin{abstract}
PURPOSE We wanted to identify characteristics of adults who do not have a usual source of care and then stratify the analysis by those who prefer vs those who do not prefer to have a usual source of care.

METHODS We analyzed data from a nationally representative sample of 9,011 adults to identify characteristics of those more likely to not have a usual source of care. Based on stated reasons for lacking a usual source of care, we created 2 subpopulations of adults without a usual source of care: those who had no preference and those who did. We identified and compared characteristics of each subpopulation.
\end{abstract}

RESULTS In the year 2000, 20\% of adults did not have a usual source of care. Among all adults, lack of insurance (odds ratio [OR] $=3.2 ; 95 \%$ confidence interval $[\mathrm{Cl}], 2.6-3.9)$ was independently associated with lacking a usual source of care, as were male sex $(\mathrm{OR}=2.1 ; 95 \% \mathrm{Cl}, 1.7-2.4)$, excellent reported health $(\mathrm{OR}=$ $2.0 ; 95 \% \mathrm{Cl}, 1.2-3.2$ ), younger age (for ages $18-29$ years, $\mathrm{OR}=4.1 ; 95 \% \mathrm{Cl}$, 3.15.4) and Hispanic ethnicity (OR $=1.5 ; 95 \% \mathrm{Cl}, 1.2-1.9)$. Of those without a usual source of care, $72 \%$ cited reasons indicating no preference to have one. Associations among such respondents were similar to those found among adults as a whole. Among respondents who preferred to have a usual source of care, however, the sex of the respondent became less significant, lack of insurance became more significant, and reported health status became nonsignificant.

CONCLUSIONS Most adults who lack a usual source of care do so for reasons of preference, evidently placing little value on having a usual source of care. Helping these persons have a usual source of care will likely require different interventions than needed to help those who want a usual source of care but cannot get one.

Ann Fam Med 2006;4:359-365. DOI: 10.1370/afm.557.

\section{INTRODUCTION}

usual source of care is important for a person's access to health care
and provides more effective and efficient health care. ${ }^{1}$ Patients who
have a usual source of care receive more preventive services, for example, and have better control of chronic medical conditions, such as hypertension. ${ }^{2-5}$ Despite such benefits, many adults in the United States do not have a usual source of care. In 2001, an estimated 52 million Americans had no usual source of care. ${ }^{6}$ An access goal in the Healthy People 2010 initiative is to decrease this number by approximately 40 million adults. ${ }^{7}$

It generally is assumed that those who lack a usual source of care do so because they face cost or other access barriers. In attempts to understand these barriers and the populations they affect, previous studies have compared characteristics of persons who have a usual source of care with those who do not. These studies have found that younger adults, Hispanics, blacks, and men are less likely than older adults, non-Hispanic whites, and women to have a usual source of care.$^{8-10}$ Additionally, studies have shown that persons reporting excellent health and those without insurance are less likely to have a usual source of care. ${ }^{8,11}$ 
Many adults, however, may not have a usual source of care simply because they have little or no desire for one. Although we are not aware of studies that directly asked participants whether they prefer a usual source of care, there are studies that have asked participants their reasons for not having a usual source of care. Responses indicate that most adults without a usual source of care place little value on having one or simply do not want one. ${ }^{8}$ Although approximately $10 \%$ of adults cite affordability as their reason for not having a usual source of care, the most common reason given is that they are seldom or never sick, which indirectly indicates that they do not value a usual source of care unless ill. ${ }^{8,9}$

The objective of this study was to identify the factors associated with not having a usual source of care among adults as a whole and then among adults stratified by preference - that is whether their stated reasons for not having a usual source of care suggested a preference for having a usual source of care. Such information will help assess whether different strategies are needed for helping more patients have a usual source of care based on their preferences for one.

\section{METHODS}

\section{Medical Expenditure Panel Survey}

We conducted a secondary analysis of data from the Medical Expenditure Panel Survey Household Component (MEPS-HC). MEPS is a longitudinal survey conducted to generate nationally representative estimates of health care use and expenditures for the United States civilian noninstitutionalized population, with oversampling of Hispanics and blacks. ${ }^{12}$ The 2000 MEPS-HC consists of 12,280 households, comprised of 23,839 adults who initially participated in the 19981999 National Health Interview Survey.

Households selected for the 2000 MEPS sample were interviewed 5 times in their place of residence during a 2.5 -year period. The data used in this analysis were gathered in 2 rounds of data collected in 2000. All adults in sample households completed a self-administered questionnaire addressing their health behaviors and health opinions. For the questions pertaining to usual source of care, family respondents were interviewed and reported for themselves as well as for their family members. Information regarding demographic characteristics, health conditions, health status, use of medical care services, and health care costs was also collected in this manner. Because reports of reasons for why someone does not have a usual source of care may not be accurate when reported by a family member, we restricted analysis to those who responded for themselves. The overall pooled response rate was $66 \%$. After excluding those who did not respond for themselves and those less than 18 years of age, 9,011 adults were included in this analysis.

\section{Study Variables}

The main outcome variable was respondents' selfreport of whether they had a usual source of care, defined as "a particular doctor's office, clinic, health center, or other place one goes to if one is sick or needs advice about health." Similar definitions are used in other national surveys. ${ }^{13}$

Adults who reported they did not have a usual source of care were also asked to indicate their primary reason for not having one. We used this information to create 2 subpopulations of adults who reported they did not have a usual source of care at the time of the survey: those who preferred a usual source of care and those who had no preference. Respondents who indicated any of the following reasons were considered as having no preference for a usual source of care: (1) went to different places for different needs, (2) did not use physicians or treated themselves, and (3) were seldom or never sick. In considering whether to include those reporting not having a usual source of care because they were seldom or never sick in the no-preference group, we reasoned that if they valued a usual source of care for preventive or well-care but faced barriers, then their appropriate primary reason would have been that they could not afford a usual source of care or that none was available. A response that being seldom or never sick when asked why one does not have a usual source of care for health needs (which explicitly included advice about health) would indicate either little or no preference for a usual source of care for wellcare and preventive health services, or a lack of desire or perceived need for preventive health services.

Potential explanatory variables for not having a usual source of care were selected from the MEPS data file based on the Andersen model of health care access and on previous studies identifying correlates of having a usual source of care. ${ }^{9-11,14}$ Selected variables were sex, age, race/ethnicity, education, marital status, income, insurance status, perceived health status, region of country, and metropolitan vs nonmetropolitan residence.

\section{Statistical Analysis}

The statistical software program Stata 8.0 (Stata Corporation, College Station, Tex) was used for all analyses, with incorporation of appropriate population weights, primary sampling units, and strata adjustments to account for the MEPS complex survey design.

Univariate analysis was conducted by determining weighted percentages. Bivariate analyses of the associations between the outcome (not having a usual source of care) and each of the potential explanatory variables 
were tested for significance using Pearson's $\chi^{2}$. For each stratum of risk factor variable, we report weighted percentages of persons who lacked a usual source of care.

Multivariable analysis using logistic regression was conducted with all independent variables for the entire population of respondents with not having a usual source of care as the outcome. We repeated the analyses to identify the factors associated with not having a usual source of care among respondents who had no preference by examining differences between characteristics of respondents who had a usual source of care and those who did not and were classified as having no preference for one. Finally, to identify the factors associated with not having a usual source of care among the population of those who likely preferred one, we repeated the logistic model to assess differences in characteristics between those who had a usual source of care and those who did not have but evidently preferred to have one.

This study was approved by the Public Health Institutional Review Board of the University of North Carolina at Chapel Hill.

\section{RESULTS}

Approximately two thirds of the weighted respondent sample was female (Table 1). Most had a high school or additional education, were or had been married, reported very good or excellent health, and had private health insurance. More than $80 \%$ lived in a metropoli$\tan$ (urban) area.

\section{Groups Who Did Not Have a Usual Source of Care}

A total of $20 \%$ of all adults reported they did not have a usual source of care (Table 2 ). The proportion of those who did not have a usual source of care decreased with age, from $36.4 \%$ of those aged 18 to 29 years to $8.0 \%$ of those aged 60 years and older. More than $28 \%$ of men compared with $15.6 \%$ of women reported not having a usual source of care. Approximately $47 \%$ of adults without insurance did not have a usual source of care. Other groups less likely to have a usual source of care were blacks and Hispanics, those either never married or divorced, adults reporting excellent health, and those living in the South and the West and in metropolitan areas.

\section{Factors Independently Associated with Not Having a Usual Source of Care}

Among the entire (weighted study) population, characteristics associated with not having a usual source of care, while controlling for all other factors, are shown in Table 3. After adjusting for other potential characteristics, the associations with age persisted,

\begin{tabular}{|c|c|}
\hline Characteristic & Weighted \% \\
\hline Female & 66.5 \\
\hline \multicolumn{2}{|l|}{ Age-group } \\
\hline $18-29 y$ & 17.8 \\
\hline $30-39 y$ & 22.0 \\
\hline $40-49 y$ & 21.1 \\
\hline $50-59 y$ & 15.5 \\
\hline $60 y$ and older & 23.5 \\
\hline \multicolumn{2}{|l|}{ Race/ethnicity } \\
\hline White/other & 78.3 \\
\hline Black & 12.0 \\
\hline Hispanic & 9.7 \\
\hline \multicolumn{2}{|l|}{ Education } \\
\hline$<$ High school & 18.2 \\
\hline High school graduate & 31.6 \\
\hline Some college & 23.2 \\
\hline College graduate & 27.0 \\
\hline \multicolumn{2}{|l|}{ Annual income } \\
\hline$<\$ 25,000$ & 54.5 \\
\hline$\$ 25,000-\$ 50,000$ & 29.4 \\
\hline$>\$ 50,000$ & 16.1 \\
\hline \multicolumn{2}{|l|}{ Marital status } \\
\hline Married & 48.5 \\
\hline Never married & 23.1 \\
\hline Divorced & 16.2 \\
\hline Widowed & 10.0 \\
\hline Separated & 2.2 \\
\hline \multicolumn{2}{|l|}{ Insurance } \\
\hline None & 11.2 \\
\hline Public & 14.4 \\
\hline Private & 74.1 \\
\hline \multicolumn{2}{|l|}{ Reported health status } \\
\hline Excellent & 16.8 \\
\hline Very good & 37.0 \\
\hline Good & 31.0 \\
\hline Fair & 12.2 \\
\hline Poor & 2.9 \\
\hline \multicolumn{2}{|l|}{ Region of country } \\
\hline Northeast & 19.2 \\
\hline Midwest & 23.1 \\
\hline South & 35.2 \\
\hline West & 22.5 \\
\hline \multicolumn{2}{|l|}{ Urban/rural location } \\
\hline Urban & 81.5 \\
\hline Rural & 18.5 \\
\hline
\end{tabular}

Note: Unweighted number of observations; $n$ per category varied from 8,926 to 9,011 because of missing data.

with younger adults more likely to be without a usual source of care. Other than young age, the independent characteristic most strongly associated with not having a usual source of care was having no insurance $(\mathrm{OR}=$ $3.2,95 \%$ confidence interval $[\mathrm{CI}], 2.6-3.9)$. The association with race/ethnicity remained for Hispanics (OR $=1.5 ; 95 \% \mathrm{CI}, 1.2-1.9)$ but not for blacks. Respondents 


\begin{tabular}{|c|c|c|c|c|c|c|}
\hline $\begin{array}{l}\text { Demographic } \\
\text { Characteristic }\end{array}$ & $\begin{array}{l}\text { All Adults } \\
\text { (n=8,851) }\end{array}$ & $P$ Value* & $\begin{array}{l}\text { Adults With } \\
\text { USC or Had } \\
\text { No Preference } \\
\text { (n }=8,333)\end{array}$ & $P$ Value* & $\begin{array}{l}\text { Adults With or } \\
\text { Preferred USC } \\
(n=7,643)\end{array}$ & $P$ Value* \\
\hline Entire group & 20.0 & & 15.2 & & 6.6 & \\
\hline Sex & & $\geq .001$ & & $\geq .001$ & & $\geq .05$ \\
\hline Male & 28.6 & & 24.2 & & 7.7 & \\
\hline Female & 15.6 & & 10.7 & & 6.1 & \\
\hline Age-group & & $\geq .001$ & & $\geq .001$ & & $\geq .001$ \\
\hline $18-29 y$ & 36.4 & & 29.0 & & 14.2 & \\
\hline $30-39 y$ & 25.8 & & 19.9 & & 9.1 & \\
\hline $40-49 y$ & 17.5 & & 13.1 & & 5.8 & \\
\hline $50-59 y$ & 14.3 & & 11.3 & & 3.8 & \\
\hline$\geq 60 y$ & 8.0 & & 5.8 & & 2.5 & \\
\hline Race/ethnicity & & $\geq .001$ & & $\geq .001$ & & $\geq .001$ \\
\hline White/other & 18.2 & & 13.9 & & 5.7 & \\
\hline Black & 21.0 & & 16.6 & & 6.3 & \\
\hline Hispanic & 33.3 & & 24.4 & & 14.9 & \\
\hline Education & & NS & & NS & & NS \\
\hline$<$ High school & 21.5 & & 15.7 & & 8.0 & \\
\hline High school graduate & 19.2 & & 15.2 & & 5.5 & \\
\hline Some college & 20.4 & & 15.9 & & 6.4 & \\
\hline College graduate & 19.3 & & 14.1 & & 7.0 & \\
\hline Annual income & & NS & & NS & & $\geq .05$ \\
\hline$<\$ 25,000$ & 20.3 & & 14.8 & & 7.6 & \\
\hline$\$ 25,000-\$ 50,000$ & 19.4 & & 15.5 & & 5.5 & \\
\hline$>\$ 50,000$ & 19.6 & & 16.0 & & 5.4 & \\
\hline Marital status & & $\geq .001$ & & $\geq .001$ & & $\geq .001$ \\
\hline Married & 15.5 & & 11.3 & & 5.4 & \\
\hline Never married & 33.6 & & 27.5 & & 11.4 & \\
\hline Divorced & 21.0 & & 16.4 & & 6.6 & \\
\hline Widowed & 8.1 & & 5.7 & & 2.7 & \\
\hline Separated & 20.0 & & 11.9 & & 10.3 & \\
\hline Insurance & & $\geq .001$ & & $\geq .001$ & & $\geq .001$ \\
\hline None & 47.0 & & 36.5 & & 23.8 & \\
\hline Public & 12.2 & & 8.2 & & 4.7 & \\
\hline Private & 17.4 & & 13.8 & & 4.9 & \\
\hline Reported health status & & $\geq .001$ & & $\geq .001$ & & NS \\
\hline Excellent & 26.9 & & 23.4 & & 5.8 & \\
\hline Very good & 21.6 & & 16.6 & & 7.1 & \\
\hline Good & 17.7 & & 13.0 & & 6.2 & \\
\hline Fair & 13.0 & & 6.9 & & 7.0 & \\
\hline Poor & 12.0 & & 5.3 & & 7.4 & \\
\hline Region of country & & $\geq .001$ & & $\geq .001$ & & $\geq .001$ \\
\hline Northeast & 14.5 & & 10.8 & & 4.6 & \\
\hline Midwest & 17.0 & & 13.9 & & 4.3 & \\
\hline South & 20.5 & & 16.1 & & 6.3 & \\
\hline West & 26.9 & & 19.2 & & 11.5 & \\
\hline Urban/rural location & & $\geq .01$ & & $\geq .05$ & & $\geq .05$ \\
\hline Urban & 20.9 & & 15.8 & & 7.1 & \\
\hline Rural & 15.9 & & 12.7 & & 4.3 & \\
\hline
\end{tabular}




\section{Table 3. Factors Independently Associated with Not Having a Usual Source of Care (USC)}

\begin{tabular}{|c|c|c|c|}
\hline Characteristic & $\begin{array}{l}\text { All Adults } \\
(\mathrm{n}=8,851)\end{array}$ & $\begin{array}{l}\text { Adults With USC or } \\
\text { Had No Preference } \\
\quad(n=8,333)\end{array}$ & $\begin{array}{c}\text { Adults With or } \\
\text { Preferred USC } \\
(n=7,643)\end{array}$ \\
\hline \multicolumn{4}{|c|}{ Sex } \\
\hline Male & $2.1^{*}$ & $2.5^{*}$ & $1.3^{+}$ \\
\hline Female & 1.0 & 1.0 & 1.0 \\
\hline \multicolumn{4}{|l|}{ Age-group } \\
\hline $18-29 y$ & $4.1^{*}$ & $3.8^{*}$ & $5.3^{*}$ \\
\hline $30-39 y$ & $3.0^{*}$ & $2.8^{*}$ & $3.4^{*}$ \\
\hline $40-49 y$ & $2.0^{*}$ & $1.9^{*}$ & $2.2^{*}$ \\
\hline $50-59 y$ & $1.6^{*}$ & $1.7^{*}$ & $1.3^{\ddagger}$ \\
\hline $60 \mathrm{y}$ and older & 1.0 & 1.0 & 1.0 \\
\hline \multicolumn{4}{|l|}{ Race/ethnicity } \\
\hline Hispanic & $1.5^{*}$ & $1.4^{\S}$ & $1.5^{\dagger}$ \\
\hline Black & $1.0^{\ddagger}$ & $1.0^{\ddagger}$ & $0.96^{\ddagger}$ \\
\hline White & 1.0 & 1.0 & 1.0 \\
\hline \multicolumn{4}{|l|}{ Education } \\
\hline$<$ High school & $1.2^{\ddagger}$ & $1.5^{\S}$ & $0.65^{\ddagger}$ \\
\hline High school & $1.1^{\ddagger}$ & $1.3^{\S}$ & $0.60 \S$ \\
\hline Some college & $1.0^{\ddagger}$ & $1.2^{\ddagger}$ & $0.72^{\ddagger}$ \\
\hline College graduate & 1.0 & 1.0 & 1.0 \\
\hline \multicolumn{4}{|l|}{ Annual income } \\
\hline$<\$ 25,000$ & $0.98^{\ddagger}$ & $0.92^{\ddagger}$ & $1.2^{\ddagger}$ \\
\hline$\$ 25-\$ 50,000$ & $0.92^{\ddagger}$ & $0.91^{\ddagger}$ & $0.99^{\ddagger}$ \\
\hline$>\$ 50,000$ & 1.0 & 1.0 & 1.0 \\
\hline \multicolumn{4}{|l|}{ Marital status } \\
\hline Never married & $1.5^{*}$ & $1.6^{*}$ & $1.2^{\ddagger}$ \\
\hline Divorced & $1.3^{\S}$ & $1.4^{\S}$ & $1.2^{\ddagger}$ \\
\hline Widowed & $1.2^{\ddagger}$ & $1.2^{\ddagger}$ & $1.2^{\ddagger}$ \\
\hline Separated & $1.1^{\ddagger}$ & $0.84^{\ddagger}$ & $1.5^{\ddagger}$ \\
\hline Married & 1.0 & 1.0 & 1.0 \\
\hline \multicolumn{4}{|l|}{ Insurance } \\
\hline None & $3.2^{*}$ & $2.7^{*}$ & $4.8^{*}$ \\
\hline Public & $0.94^{\ddagger}$ & $0.86^{\ddagger}$ & $1.1^{\ddagger}$ \\
\hline Private & 1.0 & 1.0 & 1.0 \\
\hline \multicolumn{4}{|l|}{ Health status } \\
\hline Excellent & $2.0^{\S}$ & $3.7^{*}$ & $0.55^{\ddagger}$ \\
\hline Very good & $1.7^{\dagger}$ & $2.7^{\dagger}$ & $0.79 \neq$ \\
\hline Good & $1.3^{\ddagger}$ & $2.1^{\ddagger}$ & $0.74^{\ddagger}$ \\
\hline Fair & $1.1^{\ddagger}$ & $1.2^{\ddagger}$ & $1.0^{\ddagger}$ \\
\hline Poor & 1.0 & 1.0 & 1.0 \\
\hline \multicolumn{4}{|l|}{ Region of country } \\
\hline West & $2.0 *$ & $1.8^{*}$ & $2.2^{*}$ \\
\hline South & $1.5^{\S}$ & $1.6^{\S}$ & $1.2^{\ddagger}$ \\
\hline Midwest & $1.3^{\ddagger}$ & $1.4^{\ddagger}$ & $0.86^{\ddagger}$ \\
\hline Northeast & 1.0 & 1.0 & 1.0 \\
\hline \multicolumn{4}{|l|}{ Urban/rural location } \\
\hline Urban & $1.2^{\ddagger}$ & $1.2^{\ddagger}$ & $1.4^{\dagger}$ \\
\hline Rural & 1.0 & 1.0 & 1.0 \\
\hline \multicolumn{4}{|c|}{$\begin{array}{l}\text { Note: Unweighted number of observations. Odds ratios from multiple logistic regression adjusted for all } \\
\text { other characteristics in the table. }\end{array}$} \\
\hline $\begin{array}{l}* P \geq .001 \\
\text { † } P \geq .05 \\
\text { † Not significant. } \\
\S P \geq .01\end{array}$ & & & \\
\hline
\end{tabular}

living in the South or West and in metropolitan areas were also less likely to have a usual source of care than those living in the Northeast or Midwest and nonmetropolitan areas. Respondents reporting excellent or very good health were also less likely to have a usual source of care.

\section{Reasons Given for Not Having a Usual Source of Care}

More than $66 \%$ of respondents reported that their reason for not having a usual source of care was they were seldom or never sick (Table 4). The second most common reason cited was cost, indicated by $10.2 \%$. Slightly more than $3 \%$ said that they did not have a usual source of care because they went to different places for different needs, and $2.2 \%$ said that they did not use doctors or they treated themselves. By combining adults who reported that they were seldom or never sick, went to different places for different needs, and did not use doctors, we estimate that $72 \%$ of adults without a usual source of care (or $14.4 \%$ of all adults) had no preference to have a usual source of care.

\section{Stratification by Apparent Preference for Having a Usual Source of Care}

We identified the factors associated with not having a usual source of care among respondents who either had a usual source of care or indicated no preference to have one. In unadjusted analyses in this group, the factors associated with not having a usual source of care were similar to the factors found between having a usual source of care or not among adults as a whole (Table 2). Likewise, the independent associations (Table 3 ) appeared quite similar to those associations found from the same analyses conducted on the entire population. Although the associations with male $\operatorname{sex}(\mathrm{OR}=2.5 ; 95 \% \mathrm{CI}, 2.1-3.0)$ and better health (for excellent health, $\mathrm{OR}=3.7 ; 95 \% \mathrm{CI}, 1.7-7.8)$ were more 


\begin{tabular}{|c|c|}
\hline Reason & Weighted \% \\
\hline Seldom or never sick* & 66.2 \\
\hline Unable to afford & 10.2 \\
\hline Recently moved to area & 6.3 \\
\hline Other reason & 3.7 \\
\hline Go to different places for different needs* & 3.3 \\
\hline Usual source of care in area unavailable & 3.0 \\
\hline Just changed insurance & 2.5 \\
\hline Do not use doctors/treat myself* & 2.2 \\
\hline Other insurance reason & 1.5 \\
\hline Don't know where to go & 1.2 \\
\hline
\end{tabular}

pronounced, the most notable difference is that the association with education became significant. Someone with less than a high school education had 1.5 times the odds as a college graduate not to have a usual source of care.

We then identified the factors associated with not having a usual source of care among respondents who either had one or did not have one but evidently preferred to have one. In unadjusted analyses of factors associated with not having a usual source of care within this group, the associations again look largely similar (Table 2). Income, however, became significant in this group whereas reported health status became nonsignificant.

When adjusting for all other factors (Table 3 ), reported health status remained nonsignificant; however, income became nonsignificant, and having less than high school education once again became nonsignificant. The independent association with younger age became even more pronounced (for those aged 18-29 years, $\mathrm{OR}=5.3 ; 95 \% \mathrm{CI}, 3.4-8.1)$ as did the association with no insurance $(\mathrm{OR}=4.8 ; 95 \% \mathrm{CI}$, 3.5-6.4). Hispanic ethnicity and metropolitan area remained associated with not having a usual source of care among such respondents. Male sex $(\mathrm{OR}=1.3$; $95 \% \mathrm{CI}, 1.0-1.7)$ was less significantly associated, and marital status became nonsignificant.

\section{DISCUSSION}

Our findings of the correlates of not having a usual source of care among adults as a whole are consistent with those of other studies: male sex, Hispanic ethnicity, younger age, lack of health insurance, and being in excellent reported health. ${ }^{9,10}$ We also found, as shown in previous studies, ${ }^{8,9}$ that the most common reason respondents cited for lacking a usual source of care was that they were seldom or never sick. Cost was cited by only $10.2 \%$ of respondents, approximately the same percentage reported in $1996 .{ }^{9}$ Overall, $72 \%$ of the estimated 42.7 million adults without a usual source of care in 2000 apparently had little or no preference for one, and a minority (28\%) appeared to prefer to have one, if they could.

By ignoring the possibility that many adults do not have a usual source of care because they either do not want one or place low value on having one, important implications and true barriers are obscured. From this analysis, 2 subpopulations of respondents emerged from those who do not have a usual source of care. Three of 4 respondents who do not have a usual source of care appeared to have little or no preference for one. For this group, the value of a usual source of care may not be appreciated. Thus, rather than the commonly assumed need to remove cost, transportation, or other barriers to continuity of care for all those who do not have a usual source of care, a more appropriate strategy might be to teach the importance of having one. Stratified analysis shows that persons most likely to place low value on having a usual source of care are men, younger adults, Hispanics, either never married or divorced, without insurance, in better health, in the South and West, and in urban areas. Educational messages about the importance of a usual source of care might be targeted to these groups, perhaps through schools, public service messages, and the popular media.

By contrast, 1 of 3 to 4 respondents without a usual source of care seemed to value and likely want one but evidently had difficulty obtaining one. It is in this group that cost and other traditional barriers need to be addressed, as a person's sex and reported health status do not seem to be strongly associated with lacking a usual source of care. Young age is an important factor, and lack of insurance is a stronger risk factor for this group than for those who have no preference for a usual source of care.

\section{Limitations}

The MEPS includes a large, nationally representative study population, but its data are cross-sectional, which limits our ability to conclude causality underlies the statistical associations identified in this study. The following other limitations are noted.

The definition of usual source of care in the MEPS does not explicitly include preventive care, although the phrase "... or needs advice about health" should capture some aspect of prevention. Further, respondents might consider an emergency department a usual source of care. If so, then the actual number of those not having a usual source of care in the sense that interests us would be greater. This limitation is common to all studies assessing usual source of care with similarly worded survey questions to identify a usual source of care. ${ }^{4}$

Self-reported reasons for not having a usual source 
of care, while informative, are not an infallible means by which to identify barriers, whether external or personal. The reasons cited for lacking a usual source of care convey only the respondents' beliefs about why they lack one, which may not reflect actual causes; understanding the reasons for choices and actions can be biased. ${ }^{15,16}$ In this study, for example, lack of insurance was associated with not having a usual source of care for both those who wanted a usual source of care and those who did not, yet it was reported as the primary reason by few. Some may not be able to admit to themselves that they cannot afford a usual source of care and may tell themselves instead that either they are not sick and do not need a doctor or they prefer to self-treat. On the other hand, it is also possible that those who see no reason to have a usual source of care also see no reason to have health insurance. Further supporting our classification, the 2 groups we identified based on their stated reasons differed significantly in their associations with not having a usual source of care, adding a degree of discriminant validity.

Study respondents were not asked directly whether they wanted or would have preferred to have a usual source of care. We inferred their preference from their stated reasons for not having a usual source of care. We were therefore unable to establish with certainty the respondents' preference for having a usual source of care. For the purpose of this study, however, it is not important whether some responses reflected a preference and others indicated values, inclinations, wants, or desires. The point is that having a usual source of care was not particularly important to them. As far as the validity of the responses we categorized as indicative of little or no preference for a usual source of care, a previous study categorized responses similarly: those classified as not wanting a usual source of care were those who indicated that they had no health problems, used alternative health care, did not like to go to the doctor, or preferred multiple sources of care. ${ }^{8}$

In conclusion, this study suggests that most adults who lack a usual source of care do so for reasons of preference. For them, education may be the most important strategy to help them gain a usual source of care. A minority of those without a usual source of care desire one but cannot afford one or face other barriers. This disenfranchised group would benefit from removing external barriers. To reach the Healthy People 2010 goal for all people to have a usual source of care, separate strategies will be needed to help each of these groups.

To read or post commentaries in response to this article, see it online at http://www.annfammed.org/cgi/content/full/4/4/359.

Key words: Health services accessibility; personal health services; usual source of care; delivery of health care; health services research
Submitted August 10, 2005; submitted, revised, December 19, 2005; accepted January 16, 2006.

Abstracts of this work were presented at the October 2005 meeting of the North American Primary Care Research Group and the November 2005 national meeting of the Robert Wood Johnson Clinical Scholars Program.

Funding support: Support for this work was provided by the Clinical Scholars Program of the Robert Wood Johnson Foundation.

Acknowledgments: The authors would like to thank Joshua M. Thorpe, $\mathrm{MPH}, \mathrm{PhD}$, for his assistance with MEPS, and Halle Amick and Rachel Meyer for their research assistance. We thank Larry Logan for editorial assistance and the anonymous reviewers for their insightful critique and suggestions.

\section{References}

1. Starfield B, Shi L. The medical home, access to care, and insurance: a review of evidence. Pediatrics. 2004;113:1493-1498.

2. He J, Muntner P, Chen J, et al. Factors associated with hypertension control in the general population of the United States. Arch Intern Med. 2002;162:1051-1058.

3. Bindman AB, Grumbach K, Osmond D, Vranizan K, Stewart AL. Primary care and receipt of preventive services. J Gen Intern Med. 1996;11:269-276.

4. DeVoe JE, Fryer GE, Phillips R, Green L. Receipt of preventive care among adults: insurance status and usual source of care. Am J Public Health. 2003;93:786-791.

5. Moy E, Bartman BA, Weir MR. Access to hypertensive care. Effects of income, insurance, and source of care. Arch Intern Med. 1995; 155:1497-1502.

6. Pancholi M. Reasons for Lacking a Usual Source of Care: 2001 Estimates for the US Civilian Noninstitutionalized Population. Agency for Healthcare Research and Quality; Available at: http://www. meps.ahrq.gov/PrintProducts/PrintProdLookup.asp?ProductType $=$ StatisticalBrief. Accessed: 3 November 2005.

7. United States Department of Health and Human Services. Healthy People 2010. Conference ed. Washington, DC: US Department of Health and Human Services; 2000.

8. Hayward RA, Bernard AM, Freeman HE, Corey CR. Regular source of ambulatory care and access to health services. Am J Public Health 1991;81:434-438.

9. Weinick RM, Drilea SK. Usual sources of health care and barriers to care, 1996. Stat Bull Metrop Insur Co. 1998;79:11-17.

10. Corbie-Smith G, Flagg EW, Doyle JP, O'Brien MA. Influence of usual source of care on differences by race/ethnicity in receipt of preventive services. J Gen Intern Med. 2002;17:458-464.

11. Schoen C, Lyons B, Rowland D, Davis K, Puleo E. Insurance matters for low-income adults: results from a five-state survey. Health Aff (Millwood). 1997;16:163-171.

12. Cohen J. Design and Methods of the Medical Expenditure Panel Survey Household Component. Rockville, Md: Agency for Health Care Policy and Research; 1997.

13. Centers for Disease Control National Center for Health Statistics. NCHS Definitions. Available at: http://www.cdc.gov/nchs/datawh/ nchsdefs/usualsourceofcare.htm. Accessed: 8 November 2005.

14. Andersen RM. Revisiting the behavioral model and access to medical care: does it matter? J Health Soc Behav. 1995;36:1-10.

15. Pathman DE, Agnew CR. Querying physicians' beliefs in career choice studies: the limitations of introspective causal reports. Fam Med. 1993;25:203-207.

16. Miller DT, Ross M. Self-serving biases in the attribution of causality: fact or fiction? Psychol Bull. 1975;82:213-225. 